\title{
Normal Pulmonary Arterial Wedge Pressure
}

National Cancer Institute

\section{Source}

National Cancer Institute. Normal Pulmonary Arterial Wedge Pressure. NCI Thesaurus.

Code C50677.

The measurement of the mean left arterial pressure, as measured by a catheter introduced into the distal pulmonary artery, is normal. 